\title{
The study On Mechanical Properties of HDPE Hybrid Polymer based Hybrid Composites
}

\author{
Inchara $\mathrm{C}^{*} 1$, Shantharaja $\mathrm{M}^{*} 2$, Yogesh Kumar K J*3, \\ ${ }^{*}$ PG Scholar, Mechanical Engg, UVCE, Banglore University, Bengaluru, Karanataka, India. \\ \#2Associate Professor, Mechanical Engg, UVCE, Banglore University, Bengaluru, India \\ \#3Assistant Professor, Mechanical Engg, MIT, VTU, Mysore, Karnataka, India
}

\begin{abstract}
Article Info

Volume 8, Issue 6

Page Number : $140-148$

Publication Issue

November-December-2021

Article History

Accepted : 05 Nov 2021

Published : 13 Nov 2021

Polymer and their composites are used in many engineering applications as an alternate of metals, because of the parameters such as low cost, lightweightness and durability. Hybridization is a process of mixing two or more similar or dissimilar materials. It increases the performance and efficiency. In this study investigation has been made on mechanical properties of HDPE polymer based hybrid composites fabricated from the effect of various synthetic fibers(SGF,PTFE,SCF), synthetic fillers(Silica, hydroxyapatite, zirconia) by melt mixing method using twin screw extruder followed by injection molding technique. The mechanical properties of the samples such as tensile test, flextural test were measured by universal testing machine. And the impact test was performed on izod impact testing machine. The results show that the tensile strength of hybrid composite TR-4 sample increases compared to other composites. Flextural strength of sample TR- 6 shows highest flextural strength comparted to others. The impact strength increases when the filler materials $2 \%$ of zirconia and $2 \%$ of hydroxyapatite are added to composite material i,e is TR-6 sample.
\end{abstract}

Keywords: HDPE, Hybrid materials, Mechanical properties

\section{INTRODUCTION}

Materials that are used as raw material for any form of framework or manufacturing in an sorted way of engineering application. A composite material is a multiphase material, which means it was created artificially and the constituent phases must be chemically distinct and separated by unique phases. composites representing a combination of light weight and high strength abilities have gained wide acceptance as engineering materials. Research is on, to obtain composites through optimal combination of various materials that would significantly improve tribological and mechanical characteristics, which can lead to large scale replacement of metallic materials. 
In spite of all these advantages, since they are in the nascent stages of their evolution, they possess certain limitation like difficulties in fabrication and repair, lack of standardized inspection and testing procedure. Because of the possibility of high strength and modulus associated with light weight, design and fabrication variability, and improved mechanical performance, composite materials, particularly fibre reinforced polymeric composites (FRPCs), are an extremely broad and versatile class of material system for automotive and aerospace use. Glass, carbon, and aramid are the most popular fibre reinforcements in polymer composites, whereas epoxy, vinyl ester, polyester, and other matrix polymers are the most prevalent matrix materials.

Composites are made up of two or more separate phases (matrix and dispersion), each with its own bulk properties derived from the parent material or ingredients. Contemporaneous composites have developed from glass fibre for vehicle bodies to particle composites for aerospace and a range of other uses as a consequence of decades of research and revolution. Rapid research and development in composite materials has been witnessed. Composite materials have a wide range of uses in the automotive and aerospace sectors, among others. This shortcoming is compensated for by the fact that new types of composites are being developed all the time, each with its own own set of requirements, such as filled, flake, particle, and laminar composites.

Low density, excellent strength to weight ratio, good abrasion resistance, and self-lubrication are all characteristics of polymeric composites. Polymers are used as the basic matrix in polymer composites. Polyester, epoxy, low density polyethylene (LDPE), high density polyethylene (HDPE), polypropylene, and nylon acrylics are some of the most popular polymers utilised in these composites.

To improve the matrix characteristics, reinforcements modify their particular mechanical and physical properties. It alters the matrix raw material's tensile strength, compression strength, toughness, wear resistance, friction coefficient, and a variety of other characteristics. The reinforcements give the strength to the composites. Selection of the optimal reinforcement material is dependent on the property requorements of the finished part. Nowadays, fiber reinforced polymer composites play important role in structural applications. Polymer composites having high stiffnesss, lightweight, recyclable nature and higher tensile strength. The reinforcement may be either natural or synthetic fiber reinforced composite where synthetic fibers having promising material properties as compared to natural fiber composites.

Here synthetic fibers are used as reinforcement that is SGF, PTFE, SCF are selected due to has excellent balancing qualities These fibres are typically sized to allow for effective matrix bonding, which improves mechanical characteristics.

Filler is a common substance used in the manufacture of plastic goods. The purpose of filler is to alter the characteristics of the original plastic.

Filler materials are particles that are added to resins or binders (plastics, composites) to improve specific properties, reduce costs, or a combination of the two. The purpose of filler is to alter the properties of the original plastic. Elastomers and plastics are the two most important segments for filler materials. Hybrid composite is one of the burgeoning fields in the polymer industry, and it has gotten a lot of attention recently. The development of composites with filler materials for extreme loading applications is being investigated in this hybrid composite field. In terms of mechanical properties, inorganic fillers are becoming more popular in polymer composites.

Farizah hamid et al [2], have investigated the mechanical properties and thermal properties of polyamide 6/HDPE-g-MAH/High density polyethylene. Here the blend is prepared by melt compounding using a twin screw extruder followed by injection molding using HDPE-g-MAH served as compatibilizer. A series combination of PA6/HDPE with HDPE-g-MAH were blended with varied composition of 100/0, 98/2, 96/4, 94/6 and 92/8. The 
mechanical properties of the samples such as tensile test, flexural test and elongation at break were measured by universal tensile machine while hardness was measured using the Zwick Roell hardness tester.

$\mathrm{C}$ Riul et al [3] examined the processing and evaluation of the mechanical properties of glass fiber reinforced PTFE laminates. In this study, continuous glass fiber is reinforced with polytetrafluoroethylene (PTFE) laminates. Here, the modulus of elasticity and the maximum strength were determined by a threepoint bending test and tensile test using the digital image correlation technique (DIC)

BV Lingesh et al [5] examined the influence of short glass fibers on the mechanical properties of the thermoplastic mixture of polyamide66 and polypropylene (PA66 / PP). In this study, the effect of a known weight fraction of short glass fibers such as $5,10,15,20,25$

and

30 with a mixture of $80 \%$ by weight of polyamide 66 (PA66) and $20 \%$ by weight of polypropylene (PP) and for better compatibility in the matrix mix. The polymer were combined and fabricated by using barbender twin screw extruder and molded by injection molding as per ASTM. The mechanical properties such as tensile strength, flexural strength and impact strength are studied and evaluated by ASTM.

D.I. Chuko et al [7] examined the structural, mechanical and tribological properties of short carbon fiber reinforced UHMWPE matrix composites. The structural, mechanical and tribological properties of composite materials based on ultra-high molecular weight polyethylene reinforced with carbon fibers were investigated.

Moayad N. Khalaf et al [10], evaluated the mechanical properties of

(HDPE

M624) with three fillers (inorganic and organic) with regard to the effect of the filler content. (5\% to $25 \%$ ) by weight in the composite. Depending on the type of filling and mesh size, a significant improvement in the mechanical parameters was registered.

\section{METHODS AND MATERIAL}

\section{A. MATERIALS}

The materials used in the present study are listed in Table 1.

Table1: Specifications of the material used

\begin{tabular}{|l|l|l|}
\hline Sl No & Materials & Density \\
\hline 01 & HDPE & $\begin{array}{l}0.93- \\
0.97 \mathrm{~g} / \mathrm{cm}^{3}\end{array}$ \\
\hline 02 & Short E glass fiber & $2.54 \mathrm{~g} / \mathrm{cm}^{3}$ \\
\hline 03 & & $2.2 \mathrm{~g} / \mathrm{cm}^{3}$ \\
& Polytetrafluroethylene & \\
\hline 04 & Short carbon fiber & $1.76 \mathrm{~g} / \mathrm{cm}^{3}$ \\
\hline 05 & Silica & $2.19 \mathrm{~g} / \mathrm{cm}^{3}$ \\
\hline 06 & Hydroxyapatite & $3.156 \mathrm{~g} / \mathrm{cm}^{3}$ \\
\hline 07 & Zirconia & ---- \\
\hline
\end{tabular}

\section{B. SAMPLE PREPARATION}

\section{Injection moulding}

To avoid plasticization, hydrolyzing effects from humidity, and to achieve sufficient homogeneity, the polymer and fibres were dried at $80^{\circ} \mathrm{C}$ before mixing in a mixing chamber.

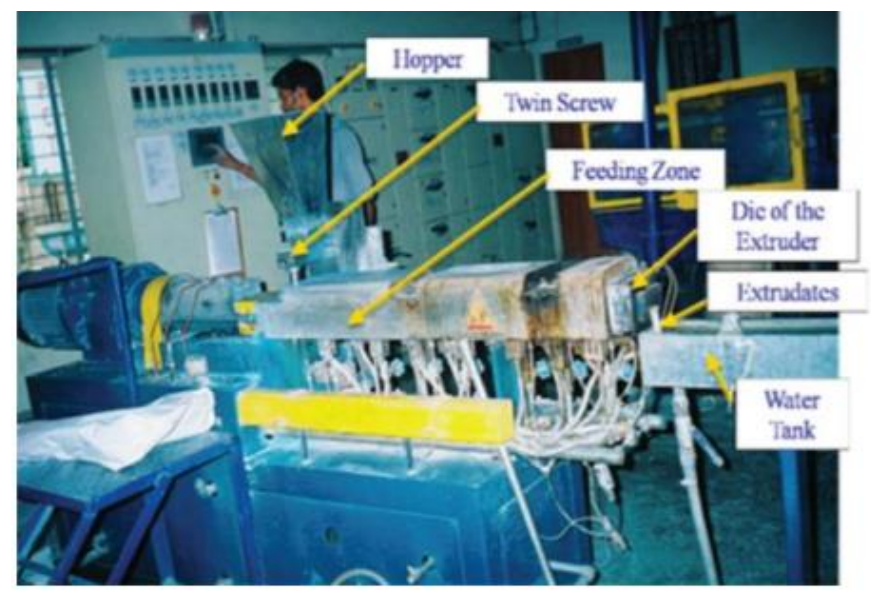

Fig 1: Barbender corotater twin screw extruder

The compositions of the samples, which include saline coated fibres SGF, SCF, and PTFE, are mixed in 
the correct proportions. As shown in Figure 4.4, the mixed materials were then extruded using a Barbender co-rotating twin-screw extruder (Model: $16 \mathrm{CME}$, SPL, chamber size $70 \mathrm{~cm} 3)$. Zone $1\left(220^{\circ} \mathrm{C}\right)$, zone $2\left(235^{\circ} \mathrm{C}\right)$, zone $3\left(240^{\circ} \mathrm{C}\right)$, zone $4\left(265^{\circ} \mathrm{C}\right)$, and zone $5\left(270^{\circ} \mathrm{C}\right)$ were the temperatures maintained in the extruder, with the temperature at the die set at $220^{\circ} \mathrm{C}$. To achieve a feed rate of $5 \mathrm{~kg} / \mathrm{hr}$, The screw speed on the extruder was set to $100 \mathrm{rpm}$. The extrudate produced was a cylindrical rod that was quenched in cold water before being palletized with a palletizing machine. Before getting the blended sample, the initial extruded materials were discarded to remove impurities from the previous extrusion stroke. All blended composite pallets were dried at $100^{\circ} \mathrm{C}$ before injection moulding. The pelletized polyblend material obtained from the corotating twin screw extruder was used to injection mould all of the test specimens. As shown in Figure 4.5, the temperatures in the two zones of the injection moulding barrel were kept at $265^{\circ} \mathrm{C}$ and $290^{\circ} \mathrm{C}$, respectively, while the mould temperature was kept at $65^{\circ} \mathrm{C}$. The screw speed was set to $10-15 \mathrm{rpm}$ and the injection pressure was set to $700-800$ bar. During injection moulding, the injection, cooling, and ejection times were all kept at 10, 35, and 2 seconds, respectively. All the molded specimens are as per ASTM standards.

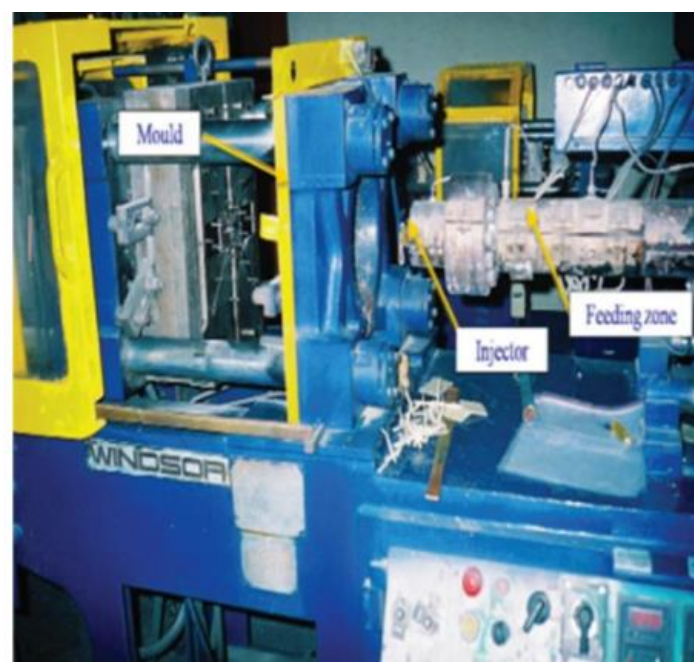

Fig 2: Injection molding machine

\begin{tabular}{|l|l|l|l|l|l|l|l|}
\hline $\begin{array}{l}\text { EXP } \\
\text { NO. }\end{array}$ & HDPE & SGF & PTFE & SCF & Silica & $\begin{array}{r}\text { Zirco } \\
\text { nium }\end{array}$ & $\begin{array}{l}\text { Hydrox } \\
\text { yapatite }\end{array}$ \\
\hline 1 & 100 & 0 & 0 & 0 & 0 & 0 & 0 \\
\hline 2 & 75 & 25 & 0 & 0 & 0 & 0 & 0 \\
\hline 3 & 73 & 25 & 2 & 0 & 0 & 0 & 0 \\
\hline 4 & 71 & 25 & 2 & 2 & 0 & 0 & 0 \\
\hline 5 & 69 & 25 & 2 & 2 & 2 & 0 & 0 \\
\hline 6 & 65 & 25 & 2 & 2 & 2 & 2 & 2 \\
\hline
\end{tabular}

\section{MEASUREMENT OF MECHANICAL PROPERTIES}

The tensile test is by far the most common mechanical test that can be performed on a material. The Kalpak universal testing machine was used to perform the tensile test in accordance with ASTM D 638. minimum three tests were conducted in each material. Test were performed at constant strain rate of $2 \mathrm{~mm} / \mathrm{min}$ at room temperature. The specimen is uniform over a gauge length (the length within which elongation measurements are taken $=72 \mathrm{~mm}$ ). Specimens were inserted into the grips and pulled until they broke. According to ASTM D638, the test speed was $2 \mathrm{~mm} / \mathrm{min}$.

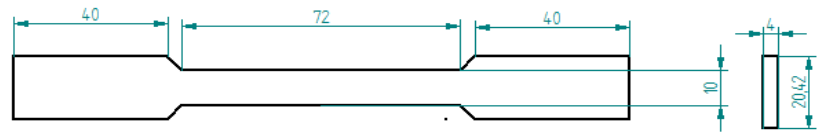

Fig 3: Standard tensile test specimen as per ASTM D638

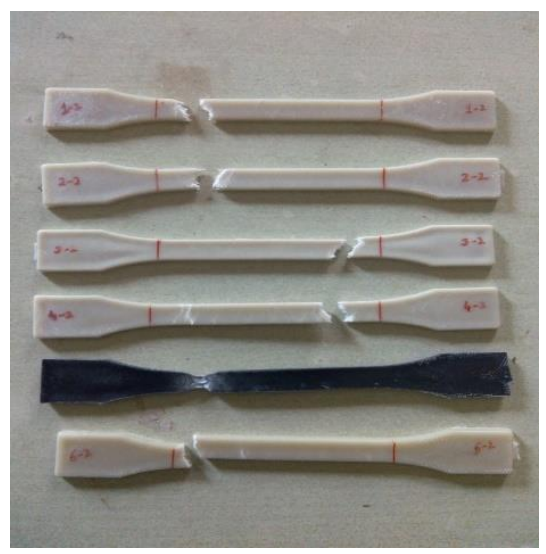

Fig 4: Tensile test specimens after testing

Table 2: composition of composite specimen used 
The flexural test determines how much force is needed to bend a beam under three-point loading. The ease of sample preparation and analysis is one of the main advantages of a three-point flextural test. To determine the flextural strength, specimen of size of $125 \mathrm{~mm} \mathrm{X} 10 \mathrm{~mm}$ X $3.75 \mathrm{~mm}$ were tested with a gauge length $60 \mathrm{~mm}$ at a maximum speed of jaws 2.5 $\mathrm{mm} / \mathrm{min}$. the fixture used for the flextural testing is as shown in figure 4.9. producing three point bending at a specified rate. The parameters for this test are the support span, the speed of loading and the maximum deflection of the test. These standards are based on the thickness of the test specimen and are defined differently by ASTM and ISO. The ASTM D790 test is terminated when the specimen reaches a deflection of $5 \%$ or when the specimen breaks before a deflection of $5 \%$.

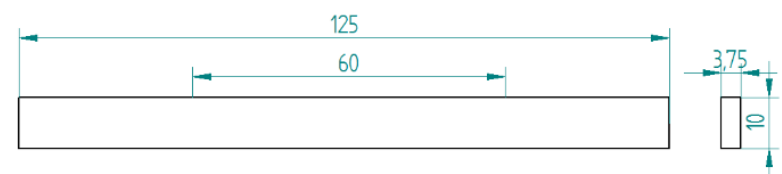

Fig 5: Flexural test specimen according to ASTM D790

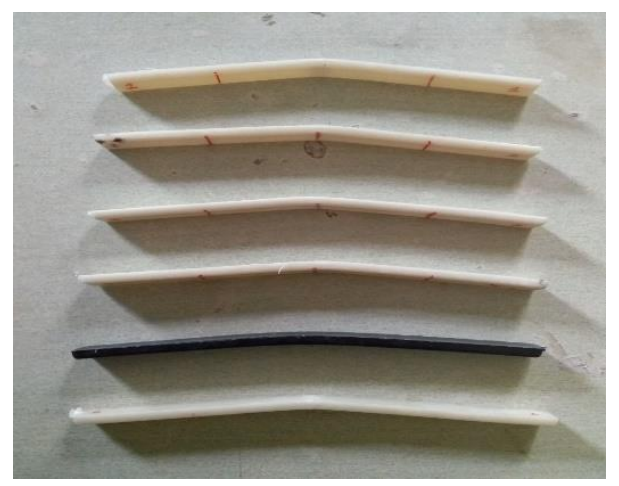

Fig 6: Flexural test specimens after testing

The energy required to break standard specimens of a specified size under specified mounting and notching parameters is referred to as impact strength. Impact tests are used to investigate a material's toughness, which is determined by its ability to absorb energy during plastic deformation.

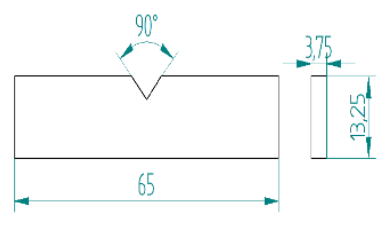

Fig (8): Izod impact specimen as per ASTMD256

Fig (9): Izod impact test specimen after testing

\section{III.RESULTS AND DISCUSSION}

\section{A. TENSILE TEST}

Table 3: Tabulation showing Maximum load, Tensile strength and Young's modulus of various specimen

\begin{tabular}{|c|c|c|c|c|c|}
\hline $\begin{array}{l}\text { compos } \\
\text { ites }\end{array}$ & $\begin{array}{c}\text { Cross } \\
\text { sectio } \\
\text { nal } \\
\text { area }( \\
\left.\mathrm{mm}^{2}\right)\end{array}$ & $\begin{array}{c}\text { Peak } \\
\text { load } \\
(\mathrm{N})\end{array}$ & $\begin{array}{l}\text { Ultim } \\
\text { ate } \\
\text { Tensil } \\
\text { e } \\
\text { Stren } \\
\text { gth } \\
(\mathrm{MPa})\end{array}$ & $\begin{array}{l}\text { Tensil } \\
\text { e } \\
\text { Modu } \\
\text { lus } \\
\text { (MPa) }\end{array}$ & $\begin{array}{l}\% \\
\text { Elonga } \\
\text { tion }\end{array}$ \\
\hline TR-1 & 37.47 & $\begin{array}{l}1019 . \\
08\end{array}$ & 25.82 & $\begin{array}{l}405.9 \\
8\end{array}$ & 2.166 \\
\hline TR-2 & 39.663 & $\begin{array}{l}1081 . \\
89\end{array}$ & 27.27 & $\begin{array}{l}353.1 \\
9\end{array}$ & 0.999 \\
\hline TR-3 & 39.218 & $\begin{array}{l}1066 . \\
95\end{array}$ & 27.2 & $\begin{array}{l}431.2 \\
1\end{array}$ & 0.888 \\
\hline TR-4 & 39.016 & $\begin{array}{l}1111 . \\
67\end{array}$ & 28.45 & $\begin{array}{l}431.0 \\
4\end{array}$ & 0.915 \\
\hline TR-5 & 39.534 & $\begin{array}{l}1087 . \\
38\end{array}$ & 27.5 & 450 & 1.022 \\
\hline TR-6 & 40.47 & 794.4 & 19.63 & $\begin{array}{l}286.7 \\
1\end{array}$ & 1.0186 \\
\hline
\end{tabular}




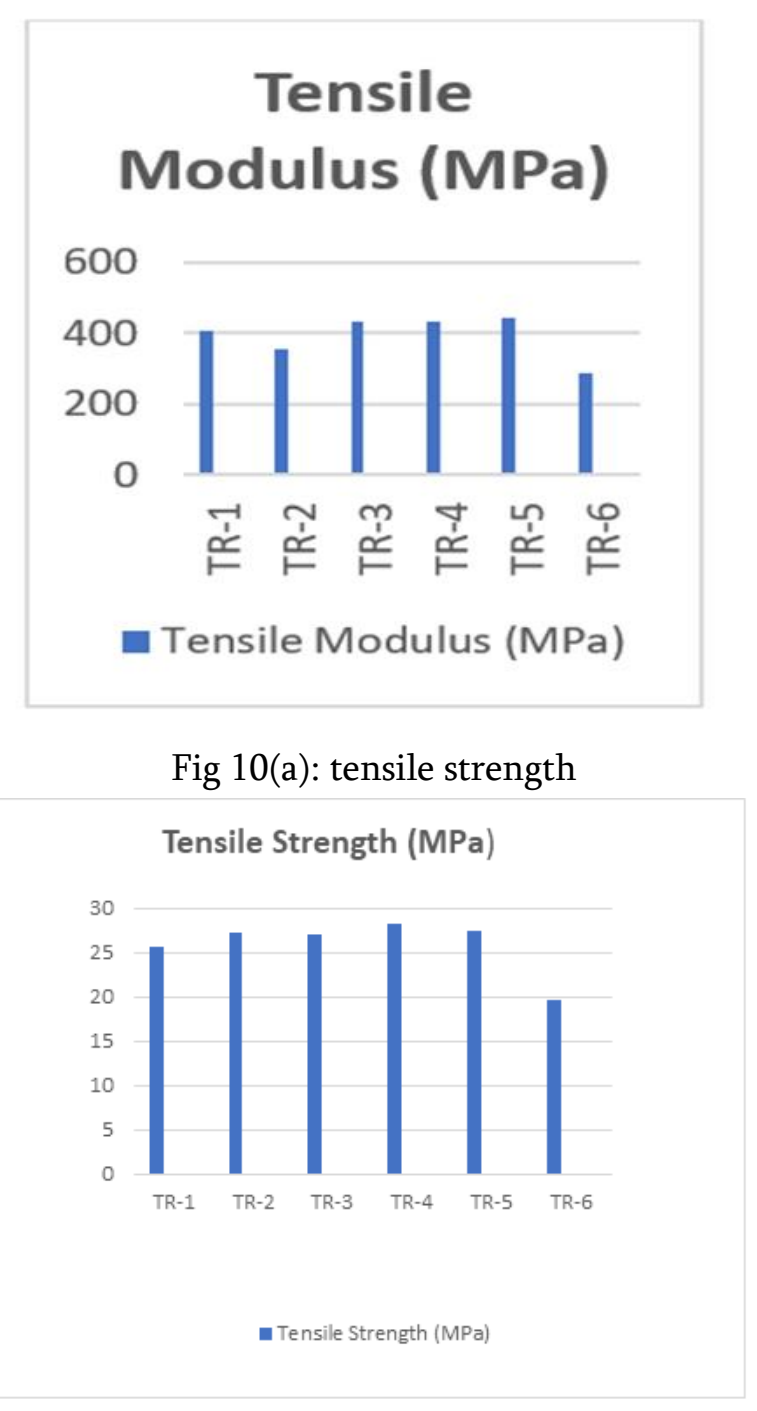

Fig 10(b): tensile modulus

\section{B. FLEXTURAL TEST}

The flexural properties of any structural element are more important. Because structural composites are prone to bending failure, the development of new composites with high flexural strength is critical.

Table 3: Tabulation showing Maximum load, Flextural strength and young's modulus obtained in the test

\begin{tabular}{|l|l|l|l|l|}
\hline $\begin{array}{l}\text { Compos } \\
\text { ites }\end{array}$ & $\begin{array}{l}\text { Cross } \\
\text { sectional } \\
\text { area }\left(\mathrm{mm}^{2}\right)\end{array}$ & $\begin{array}{l}\text { Peak } \\
\text { load } \\
(\mathrm{N})\end{array}$ & $\begin{array}{l}\text { Ultimate } \\
\text { Flexural } \\
\text { Strength } \\
(\mathrm{MPa})\end{array}$ & $\begin{array}{l}\text { Flexura } \\
\text { Modulu } \\
\mathrm{s} \\
(\mathrm{MPa})\end{array}$ \\
\hline TR-1 & 36.85 & 52.32 & 34.22 & 1615.5 \\
\hline TR-2 & 37.63 & 53.44 & 33.72 & 1058.82 \\
\hline TR-3 & 36.55 & 47.46 & 31.52 & 1068.34 \\
\hline TR-4 & 37.48 & 47.5 & 20.18 & 1315.55 \\
\hline TR-5 & 37.47 & 41.69 & 26.68 & 1211.7 \\
\hline TR-6 & 36.76 & 18.62 & 45.58 & 346.38 \\
\hline
\end{tabular}

It is noticed that sample TR-4 that is HDPE reinforced with SGF, PTFE and SCF with laminates exhibits better tensile strength as compared to base material. That is tensile strength increases from $25.82 \mathrm{MPa}$ to $28.45 \mathrm{MPa}$ which is a $10.18 \%$ increase. This shows addition of fiber to the base material HDPE have better compatability between HDPE and the fibers. It is also noticed that the tensile strength decreases when the adding the filler materials to the sample. This is due to the property of the filler material i.e, brittle nature of the material. 


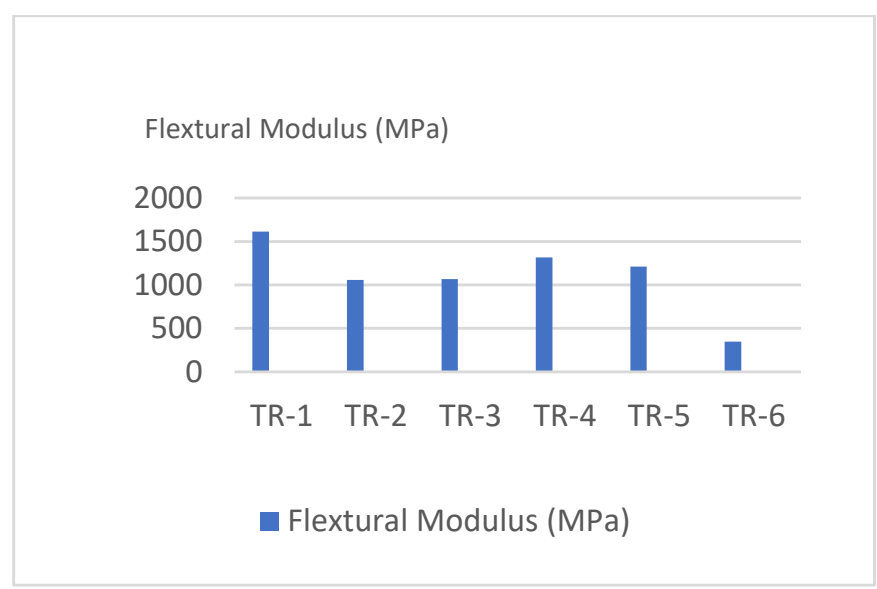

Fig 13: variation of flextural modulus of the

It is seen that the flextural strength value of hybrid composite TR-6 sample is higher compared to the base material. Thus, the composite showed an appreciable influence of zirconia, hydroxyapatite fillers. The flexural strength of TR-3 is significantly higher than TR-4 this is due to brittleness of carbon fibers in spite of their high values ultimate tensile strength. But when compared to flexural modulus it was seen that sample TR-4 gets highest modulus compared to other hybrid composites.

\section{IMPACT TEST}

Table 4: The results obtained after conducting Impact test is given

\begin{tabular}{|l|l|}
\hline Composites & $\begin{array}{l}\text { Impact strength } \\
\left(\mathrm{J} / \mathrm{m}^{2}\right)\end{array}$ \\
\hline TR-1 & 53.33 \\
\hline TR-2 & 45.45 \\
\hline TR-3 & 65.96 \\
\hline TR-4 & 58.03 \\
\hline TR-5 & 39.78 \\
\hline TR-6 & 78.41 \\
\hline
\end{tabular}

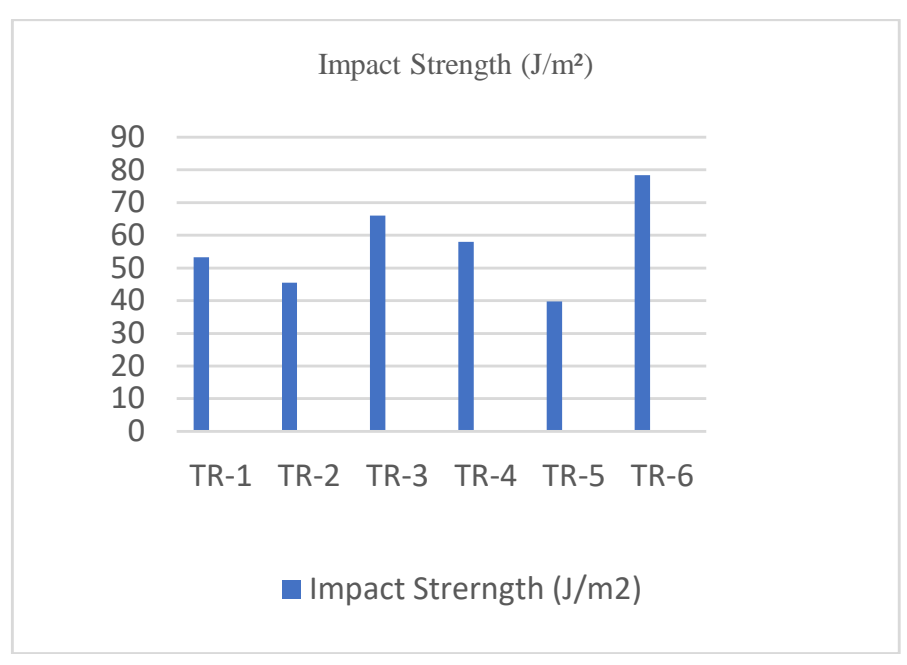

Fig 14: variation of impact strength of the specimen

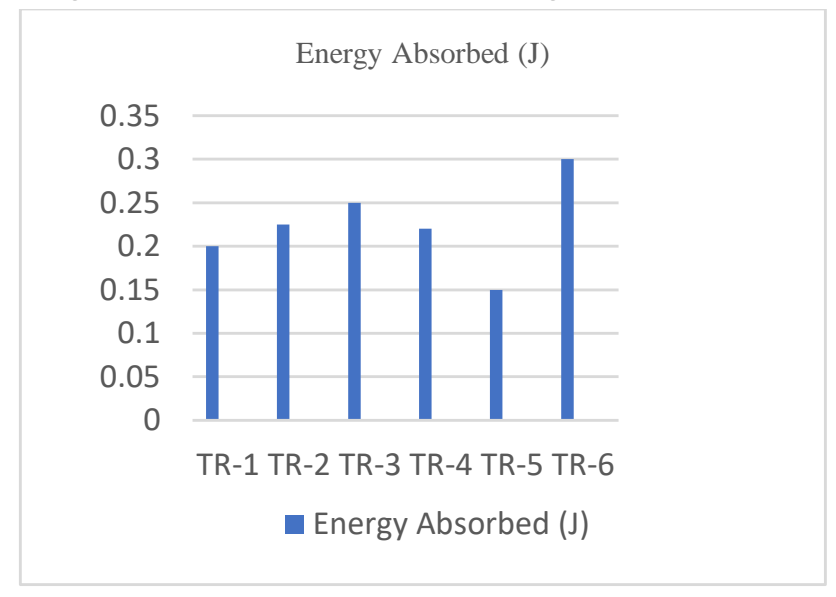

Fig 15: variation of energy absorbed of the specimens

It is found that the impact strength of TR- 6 that is $65 \%$ of HDPE, 25\% OF SGF, 2\% of PTFE, $2 \%$ of SCF sample is increases compared to other samples. It is found that the TR-5 sample has very less impact strength compared to other samples due to the addition of the filler material $2 \%$ of silica.

\section{CONCLUSION}

The current work has been undertaken, with an objective to explore the potential of the treated HDPE polymer based hybrid composites and to learn characteristic of the hybrid composite.

Tensile test - The tensile test was conducted on both the base material and the HDPE- hybrid 
composites. The tensile strength of the fibres composite material was found to be higher than that of the base material. The tensile strength of sample TR-4, which contains 71\% HDPE, $25 \%$ SGF, 2 \% PTFE, and $2 \%$ SCF, has increased. Increase in tensile strength is due to better bonding, adhering to the surface(adhesion) and dispersion of the fiber in the matrix.

But TR-6 sample shows very less tensile strength compared to others due to the addition of filler materials in the sample.

Even, the TR-5 remains exceptional case as on the comparison of the Young's modulus. It gives an highest modulus.

$>$ Flexural test - It was seen that the flexural strength of the TR- 4 sample composite material as shown a gradual decreased from 31.52 to 20.18 MPa with addition of $2 \%$ of SCF when compared to the base material. Due to the brittle property of the material.

But increases in the case of sample TR-6 as an exceptional case with addition of fillers, $2 \%$ of zirconia and $2 \%$ of hydroxyapatite shows high flexural strength when compared to others. But adverse when it comes to flexural modulus. Where TR-4 gest highest modulus.

$>$ Impact test - It was seen that the impact strength of TR- 6 is greater than that of all composite and the base material. In contrast, TR- 5 was found to have very less impact strength. Hence, it is conclude that by adding the fillers and reinforcement as in proportion of TR-6, we could increase the impact strength

\section{SCOPE OF FUTURE WORK}

Plastic is going to be a future material as a metal substitute. Here composite materials are made with use of plastic (thermoplastics). When compared to traditional materials, composites can meet a wide range of design requirements while saving significant weight and providing a high strength-to-weight ratio. At room temperature, the effect of notch on mechanical properties is investigated.

Further, the effect of temperature rise on the mechanical properties of composite materials can be studied.

- The effect of V-notch is studied here. Further the effect of different stress concentrates like circularlelliptical holes can be studied in future.

- The wear and abrasive test analysis can be studied.

- The result obtained here can be taken has a data base for future work regarding these concepts.

- Only static mechanical properties are studied, efforts can be laid in order to study the various dynamic and structural properties in the near future.

\section{REFERENCES}

[1]. Boon Peng Chang, Hazizan MD Akil, Ramdziah Md. Nasir, 2013, Mechanical and Tribological properties of Zeolite-reinforced UHMWPE Composite for Implant application, Procedia Engineering 68, pg 88-94

[2]. Farizah Hamid, Suffiyana Akhbar, K.H Ku Halim, 2013,Mechanical and Thermal properties of Polyamide 6/HDPE-g-MAH/High Density Polyethylene, Procedia Engineering 68, pg 418-424.

[3]. C. Riul, V. Tita, J.de. Carvalho, R.B.Canto, 2012,Processing and Mechanical properties evolution of glass fiber-reinforced PTFE laminates, Composite science and technology 72, pg 14511458.

[4]. Chun Yan, Hangzhau Li, Xiaoqing Zhang, Yingdan Zha, Xingu Fan, Liping Yu, 2013, Preparation and properties of continuous glass fiber reinforced anionic polyamide-6 thermoplastic composites.

[5]. B.V. Lingesh, B.M. Rudresh, B.N. Ravikumar, 2014, Effect of short glass fibers on mechanical properties of Polyamide66 and Polypropylene(PA66/PP) thermoplastic blend composites, Procedia material science 5, pg 1231-1240. 
[6]. Amit Mallik, Anil K Barik, Biswajit Pal, 2015, Comparative studies on physic-mechanical properties of composite material of low density Polyethylene and raw/Calcined Kaolin, Journal of Asian Ceramic Societies 3, pg 212-216.

[7]. D.I. Chukova, A.A. Stepashkina, A.V. Maksimkina, V.V.Tcherdyntseva, S.D. Kaloshkina, K.V. Kuskova, V.I. Bugakovb, 2015, Investigation of structure, mechanical and tribological properties of short carbon fiber reinforced UHMWPE-matrix composites, Composites part B.

[8]. Mariam A AlMaadeed, Ramazan Kahraman, P. Noorunnisa Khanam, Nabil Madi,2012, Date plam wood flour/glass fibre reinforced hybrid composite of recycled polypropylene: mechanical and thermal properties.

[9]. S L Favaro, T. A. Ganzerli, A. G. V. de Carvalho Neto, O.R.R.F. da Silva, E.Radovanovic,2010; Chemical, Morphological and Mechanical analysis of sisal fiber-reinforced recycled high-density polyethylene composites, pg 465-473.

[10]. Moayad N. Khalaf, Mechanical properties of high density polyethylene,2011.

[11]. Jagannath Biwas, Hyun Kim Chai Suk Yim, Junghwan Cho, Geom Joong Kim, and Soonja Choe 2004, Structural Effects on the tensile and Morphological properties of Zeolite-filled Polypropylene Derivative composites, pg 443-450.

[12]. Ji-Zhao Liang*1 , Quan-Quan Yang1,Effects of carbon fiber content and size on electric conductive properties of reinforced high density polyethylene composites, 1 April 2017, Pages 457-466

[13]. Chao Hua, Xinwen Liaoa, Qing-Hua Qina,*, Gang Wangb, The fabrication and characterization of high density polyethylene composites reinforced by carbon nanotube coated carbon fibers

[14]. Maryana Zagula-Yavorska, Jerzy Morgiel n , Jolanta Romanowska, Jan Sieniawski, Nanoparticles in zirconium-doped aluminide coatings

[15]. B. Naveen Kumar Reddy a, $\Uparrow$, P. Kiran b, Effect of silver oxide on hydroxy carbonated apatite formation for simulated body fluid soaked calcium phospho silicate system

[16]. A. Sampath Kumar, T. Himanshu, V. Vikashkumar, J. Shubham, S. Shyamkumar and SPS Ram pyare, Mater. Sci. Eng. C 49 (2015) 549-559.
[17]. Keun-Hwan Oha , Insung Baea , Hongkyung Leeb , Hyuk Kima , Hee-Tak Kimb, Silica-embedded hydrogel nanofiller for enhancing low humidity proton conduction of a hydrocarbon-based polymer electrolyte membrane

[18]. Harjeet S. Jaggi a , Yogesh Kumar a , Bhabani K. Satapathy a, $\Uparrow$, Alok R. Ray b , Amar Patnaik c, Analytical interpretations of structural and mechanical response of high density polyethylene/hydroxyapatite bio-composites, a Centre for Polymer Science and Engineering, Indian Institute of Technology Delhi, Hauz Khas, New Delhi 110 016, India b Centre for Biomedical Engineering, Indian Institute of Technology Delhi, Hauz Khas, New Delhi 110 016, India c Mechanical Engineering Department, NIT Hamirpur 177 005, India

[19]. C. Albanoa,* , R. Pererac , L. Catañob , A. Karamb , G. Gonzálezd,e, Prediction of mechanical properties of composites of HDPE/HA/EAA, a Universidad Central de Venezuela, Facultad de Ingeniería, Escuela de Ingeniería Química, Caracas, Venezuela b Laboratorio de Polímeros, Centro de Química, Instituto Venezolano de Investigaciones Científicas, Caracas, Venezuela c Departamento de Mecánica, Universidad Simón Bolívar, Valle de Sartenejas, Caracas, Venezuela d Lab. de Materiales, Centro de Ingeniería de Materiales y Nanotecnología, Instituto Venezolano de Investigaciones Científicas, Caracas, Venezuela e Escuela de Fisica, Facultad de Ciencias, Universidad Central de Venezuela, Caracas, Venezuela

[20]. Nischal Kharel1, Abinash Kumar Adhikari2, Abinash Bajgain3, Devaraj.E4, Mechanical Properties of HDPE Reinforced with carbon fiber Powder with and without filler addition

\section{Cite this article as :}

Inchara C, Shantharaja M, Yogesh Kumar K J, "The Study on Mechanical Properties of HDPE Hybrid Polymer Based Hybrid Composites", International Journal of Scientific Research in Science and Technology (IJSRST), Online ISSN : 2395-602X, Print ISSN : 2395-6011, Volume 8 Issue 6, pp. 140-148, November-December 2021. Available at doi $\quad:$ https://doi.org/10.32628/IJSRST21861 Journal URL : https://ijsrst.com/IJSRST21861 